\title{
Optimization of Synthesis Conditions for Carboxymethyl Cellulose from Pineapple Leaf Waste using Microwave- Assisted Heating and Its Application as a Food Thickener
}

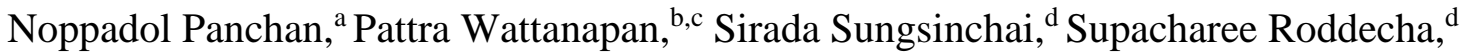
Peerapan Dittanet, ${ }^{\mathrm{d}}$ Anusorn Seubsai, ${ }^{\mathrm{d}, \mathrm{e}, \mathrm{f}}$ Chalida Niamnuy,,${ }^{\text {de,f,* }}$ and Sakamon Devahastin ${ }^{\mathrm{g}, \mathrm{h}}$

\begin{abstract}
Pineapple leaf waste, with its high cellulose content, can serve as alternative starting material for the production of carboxymethyl cellulose (CMC). In this study, synthesis conditions of CMC from pineapple leaves via the use of microwave heating were optimized. Box-Behnken design and response surface methodology were applied to schedule the experiments and to optimize the synthesis condition, respectively. Preparation of CMC was investigated by varying three factors, namely, sodium hydroxide $(\mathrm{NaOH})$ concentration, monochloroacetic acid (MCA) dose, and etherification time. The process of carboxymethylation was optimized to produce $\mathrm{CMC}$ with high degree of substitution (DS). Optimal condition for CMC synthesis was noted to be $50 \%(\mathrm{w} / \mathrm{v}) \mathrm{NaOH}$ solution, $8 \mathrm{~g}$ of $\mathrm{MCA} / \mathrm{g}$ cellulose, and etherification time of 16 min; such optimal condition resulted in the maximum DS of 0.78 . Synthesized CMC was utilized as a thickener for liquid foods (water, orange juice, milk, and mushroom cream soup) where $2 \%(\mathrm{w} / \mathrm{v})$ as-synthesized $\mathrm{CMC}$ increased the viscosity of the foods and changed their characteristics from thin to nectar-like liquids.
\end{abstract}

Keywords: Cellulose; Degree of substitution; Flow behavior; Fourier transform infrared spectroscopy; Xray diffraction; Viscoelastic properties

Contact information: a: Department of Chemical Engineering, Faculty of Engineering and Technology, Mahanakorn University of Technology, Bangkok 10530, Thailand; b: Department of Rehabilitation Medicine, Faculty of Medicine, Khon Kaen University, 123 Mittapap Road, Muang, Khon Kaen 40002, Thailand; c: Dysphagia Research Group, Khon Kaen University, Khon Kaen 40002, Thailand; d: Department of Chemical Engineering, Faculty of Engineering, Kasetsart University, Bangkok 10900, Thailand; $e$ : Center for Advanced Studies in Nanotechnology and Its Applications in Chemical, Food and Agricultural Industries, Kasetsart University, 50 Ngam Wong Wan Road, Chatuchak, Bangkok 10900, Thailand; f: Research Network of NANOTEC-KU on Nano Catalysts and Nano Materials for Sustainable Energy and Environment, Kasetsart University, 50 Ngam Wong Wan Road, Chatuchak, Bangkok 10900, Thailand; g: Advanced Food Processing Research Laboratory, Department of Food Engineering, Faculty of Engineering, King Mongkut's University of Technology Thonburi, 126 Pracha u-tid Road, Tungkru, Bangkok 10140, Thailand; $h$ : The Academy of Science, The Royal Society of Thailand, Dusit, Bangkok 10300, Thailand; *Corresponding author:fengcdni@ku.ac.th

\section{INTRODUCTION}

Pineapple is an important agricultural produce that has widely been cultivated in Thailand and other countries in Southeast Asia. In 2019, pineapple production in Thailand was estimated to be 1.82 million metric tons (Office of Agricultural Economics 2020), accounting for $6 \%$ of the global pineapple production (Shahbandeh 2021). After the produce has been harvested, tremendous amounts of pineapple leaves, which account for 
as much as $70 \%$ of the total mass of pineapple plant, is discarded as agricultural waste, causing various problems to farmers and the environment (Kengkhetkit and Amornsakchai 2012; Phan et al. 2021). Finding a means to utilize such a residue is clearly of interest, as it would reduce the volume of waste accumulation, minimizing the environmental impact and adding value to the waste. Since pineapple leaves contain higher than $80 \mathrm{wt} \%$ cellulose (dry mass), the leaves could potentially be used as a starting raw material for the production of renewable and biodegradable materials (Cherian et al. 2010). Numerous works have indeed reported the use of cellulose from pineapple leaves in various applications, e.g., as reinforcement fiber in thermoplastics (Chollakup et al. 2011; Kengkhetkit and Amornsakchai 2012; Balakrishnan et al. 2018), cellulose nanocrystals for food packaging (Santos et al. 2013; Sasikala and Umapathy 2018), cellulose nanofibers (Mahardika et al. 2018), and adsorbents for heavy metals removal (Tangtubtim and Saikrasun 2019). In some application areas such as food, pharmaceutical and medical, however, cellulose must be modified into cellulose derivatives, e.g., carboxymethyl cellulose, methyl cellulose, ethyl cellulose, hydroxypropyl cellulose, and cyano-ethyl cellulose, prior to its use.

Among cellulose derivatives, sodium carboxymethyl cellulose (CMC) is one of the most important. CMC is generally prepared from natural cellulose, which is modified with the creation of ether linkages to carboxylic acid groups. CMC has broad applications in the food, pharmaceutical, cosmetic, paint, textile, paper, and consumer product industries (Abe et al. 2018). The global market size of CMC was valued at $\$ 1,735.2$ million in 2018 and is forecasted to reach approximately $\$ 2,370.6$ million by 2026 , with a compound annual growth rate of $4.1 \%$ (Chouhan et al. 2019). In the food industry, CMC is widely used as a stabilizer, thickener, and moisture binder for improving the stability and texture of various foods and beverages (Yu et al. 2019). Since CMC is tasteless and odorless and can form a clear solution without any cloudiness or opacity, it is also widely used to prevent separation due to sedimentation of suspended particles and to promote desirable textural attributes and mouth feel. Increasing application of CMC in a wide variety of food and beverage products, e.g., milk, ice cream, bakery products, candies, chewing gums, margarine, and peanut butter, as a thickening agent and/or stabilizer has naturally increased the demand for CMC (Bayarri et al. 2009; Arancibia et al. 2016; Chouhan et al. 2019). While CMC is typically produced from cotton and wood pulp cellulose (Chouhan et al. 2019), several studies attempted to prepare CMC from other lignocellulosic materials such as banana pseudo stem (Adinugraha et al. 2005), sago waste (Pushpamalar et al. 2006), cotton stalk (Zhang et al, 2011), rice straw (Panchan and Niamnuy 2015), brewer's spent grain (Santos et al. 2015), corn stalk (Shui et al. 2017), seaweed cellulose (Lakshmi et al. 2017), sugarcane bagasse (Asl et al. 2017), and asparagus stalk end (Klunklin et al. 2021).

Despite the aforementioned increasing demand, synthesis of CMC by use of conventional methods requires lengthy reaction time to achieve adequate yield and degree of substitution (DS). Microwave heating, which is known for its rapid heating capability, is therefore of interest. Microwave-assisted synthesis methods have indeed been reported to provide a number of advantages over the conventional synthesis means (Kappe 2004); such advantages include shortened reaction time and increased product yield and purity (Santos et al. 2015; Panchan et al. 2018). Nevertheless, there is so far no information on microwave-assisted synthesis of CMC from pineapple leaf waste.

The objectives of this work were to synthesize CMC from pineapple leaf waste using microwave-assisted heating and to investigate the effects of various key parameters, i.e., sodium hydroxide $(\mathrm{NaOH})$ concentration, monochloroacetic acid (MCA) dose, and 
etherification time, on the DS of prepared CMC. Optimization of the synthesis condition was conducted to maximize the DS. The work also highlighted the significance of the rheological properties and potential of the as-synthesized CMC as a food thickener.

\section{EXPERIMENTAL}

\section{Materials}

Pineapple leaves (Smooth Cayenne variety) were collected from a local field in Prachuap Khiri Khan Province, Thailand. Sodium hydroxide and sodium chlorite were purchased from Ajax Finechem (Auckland, New Zealand). Monochloroacetic acid was obtained from Sigma-Aldrich (St. Louis, MO, USA). Glacial acetic acid was purchased from Merck KGaA (Darmstadt, Germany). Ethanol was purchased from RCI Labscan (Bangkok, Thailand). All solutions were prepared in deionized water (DI water). Commercial CMC with DS of 0.83 was domestically purchased from Krungthepchemi (Bangkok, Thailand).

\section{Isolation of Cellulose from Pineapple Leaves}

Pineapple leaves were washed to remove minerals; the leaves were then dried and ground into powder prior to the isolation of cellulose as per the methods of Mandal et al. (2015) with some modification. The ground pineapple leaves were bleached with $0.7 \%$ (w/v) sodium chlorite $\left(\mathrm{NaClO}_{2}\right)$ at $70{ }^{\circ} \mathrm{C}$ for $5 \mathrm{~h}$. The bleaching mixture was cooled to 10 ${ }^{\circ} \mathrm{C}$ to avoid free-gaseous chlorine. Precipitated bleached pineapple leaves were washed with tap water until they were free of chlorine odor.

For the alkali treatment step, the bleached pineapple leaves were soaked in 5\% (w/v) $\mathrm{NaOH}$ solution for $24 \mathrm{~h}$ at room temperature and then heated at $90{ }^{\circ} \mathrm{C}$ with gentle stirring for $2 \mathrm{~h}$. Precipitated cellulose was filtered and washed with tap water until neutrality had been reached. The product was dried at $60{ }^{\circ} \mathrm{C}$ overnight and kept in a vacuum container. The degree of $\alpha$-cellulose contained in the isolated cellulose product was determined according to the TAPPI T203 om-88 (1992) standard.

\section{Synthesis of CMC from Isolated Cellulose}

The synthesis methods of CMC were those of Mandal et al. (2015) and Panchan et al. (2018) with appropriate modification. The first synthesis step was alkalization in which $4.0 \mathrm{~g}$ of isolated cellulose was added into a three-neck round bottom flask, which was subsequently placed in a modified domestic microwave oven (LG, MS2343DAR, Seoul, Korea) equipped with a condenser and glass agitator. Two hundred $\mathrm{mL}$ of ethanol was added along with $50 \mathrm{~mL}$ of either 10,30 or $50 \mathrm{~g} / 100 \mathrm{~mL}$ aqueous $\mathrm{NaOH}$ solution. The mixture was agitated at $450 \mathrm{rpm}$ for $30 \mathrm{~min}$ at room temperature to complete the alkalization reaction. Etherification reaction was then conducted by adding 1, 4.5, or $8 \mathrm{~g}$ of $\mathrm{MCA} / \mathrm{g}$ cellulose, with an etherification period of 2 , 16, or $30 \mathrm{~min}$ at input microwave power of $320 \mathrm{~W}$. After the reaction, the content was suspended in $80 \%(\mathrm{v} / \mathrm{v})$ ethanol, neutralized with glacial acetic acid, filtered, and thrice washed with $70 \%$ (v/v) ethanol. The obtained $\mathrm{CMC}$ cake was dried at $60^{\circ} \mathrm{C}$ for $6 \mathrm{~h}$ and kept in a vacuum container until further analysis and use. 
A total of 17 experiments were scheduled using the Box-Behnken design. Response surface methodology (RSM) was employed to analyze the experimental data to determine the optimal synthesis condition using Design Expert ${ }^{\circledR} 9.0$ (Stat-Ease Inc., Minneapolis, MN, USA). DS and purity of the prepared CMC were determined using ASTM D1439-94 standard method (ASTM 1994).

\section{Characterization of As-Synthesized CMC}

Functional groups of cellulose and CMC samples were identified using Fourier transform infrared (FTIR) spectroscopy. Prior to the analysis, a sample was dried overnight at $60{ }^{\circ} \mathrm{C}$. Pellets were made of $0.2 \mathrm{mg}$ of the sample ground with $2.0 \mathrm{mg}$ of $\mathrm{KBr}$; the mixture was compressed to form a transparent disk. FTIR spectra were recorded using an FTIR spectrometer (Bruker, Tensor 27, Karlsruhe, Germany) within the wavenumber range of 400 to $4000 \mathrm{~cm}^{-1}$.

XRD patterns of isolated cellulose, alkali-cellulose and as-synthesized CMC samples were determined using an X-ray diffractometer (Bruker, D8 Advance, Karlsruhe, Germany) equipped with $\mathrm{CuK} \alpha$ radiation in the $2 \theta$ range of 10 to $50^{\circ}$ with a scan rate of $5^{\circ} \mathrm{min}^{-1}$ at room temperature. Crystallinity index (CrI) of a sample was calculated as per Eq. 1:

$$
\mathrm{CrI}=\frac{I_{200}-I_{\mathrm{am}}}{I_{200}} \times 100
$$

where $I_{200}$ is the maximum diffraction intensity at (200) lattice peak and $I_{\mathrm{am}}$ is the minimum diffraction intensity between (110) and (200) lattice peaks (Wei et al. 2019).

Morphologies of untreated leaves as well as those of cellulose and as-synthesized CMC were investigated using a scanning electron microscope (JEOL, JSM7001F, Tokyo, Japan). A dried sample was coated with an ultrathin layer of gold in a sputter coater prior to the scanning electron microscopy.

\section{Determination of Solubility and Viscoelastic Properties}

The methods for determining the solubility of CMC were those of Ambjörnsson et al. (2013) with some modification. Different masses of as-synthesized CMC powder were dissolved in $100 \mathrm{~mL}$ of DI water and stirred at $1200 \mathrm{rpm}$ for $2 \mathrm{~h}$. Each solution was filtered with gentle suction through a sintered glass crucible porosity no. 3 to separate the gel part and undissolved residuals. The insoluble part was dried at $105^{\circ} \mathrm{C}$ until reaching a constant mass. The solubility was calculated as per Eq. 2,

$$
\text { Solubility }(\%)=\frac{W_{\mathrm{f}}}{W_{\mathrm{i}}} \times 100
$$

where $W_{\mathrm{i}}$ is the initial mass of the dried as-synthesized CMC sample and $W_{\mathrm{f}}$ is the mass of the remaining dried undissolved part after extraction with water.

Viscoelastic properties of CMC suspension were determined by dissolving CMC in DI water at a concentration of $2 \%(\mathrm{w} / \mathrm{v})$. A rheometer (TA instrument, ARES-G2, New Castle, DE, USA) equipped with 40-mm sandblasted parallel plates was used; the gap between the plates was fixed at $1.0 \mathrm{~mm}$. Each sample was measured by applying a strain sweep with frequency sweep in the linear viscoelastic region. The strain sweep test was conducted at a frequency of $1 \mathrm{~Hz}$ over the range of 0.1 to $500 \%$. Storage modulus $\left(G^{\prime}\right)$ and loss modulus $\left(G^{\prime \prime}\right)$ were measured as a function of the angular frequency $(\omega=0.1$ to 100 $\operatorname{rad~s}^{-1}$ ) at $30 \%$ strain. Flow behavior of the suspension under steady-state relationship 
between the shear stress and shear rate is expressed by fitting the results to the Power-law model shown in Eq. 3,

$$
\sigma=K \dot{\gamma}^{n}
$$

where $\sigma$ is the shear stress $(\mathrm{Pa}), j$ is the shear rate $\left(\mathrm{s}^{-1}\right), K$ is the consistency coefficient $\left(\mathrm{Pa} \cdot \mathrm{s}^{\mathrm{n}}\right)$, and $n$ is the flow behavior index (dimensionless).

The effect of CMC on the behavior of liquid food samples was evaluated by measuring their viscosity change after adding 2\%(w/v) CMC. The CMC solution was slowly poured into four different liquid food samples: drinking water, UHT whole milk (Thai-Denmark, Saraburi, Thailand), orange juice (Tipco, Bangkok, Thailand), and mushroom cream soup (Roza, Samut Prakan, Thailand). Each content was continuously stirred at $400 \mathrm{rpm}$ for $5 \mathrm{~min}$. All the food samples were measured for their viscosity using a viscometer (Brookfield Engineering, RV DVII, Middleboro, MA, USA) equipped with spindle 27 at a shear rate of $51 \mathrm{~s}^{-1}$ and speed of $55 \mathrm{rpm}$.

\section{RESULTS AND DISCUSSION}

\section{Optimization of CMC Synthesis Condition}

The isolation of cellulose was undertaken to observe lignocellulosic composition in pineapple leaves. The isolated cellulose from pineapple leaves were composed of $\alpha$ cellulose, hemicelluloses, lignin and non-cellulosic substances, accounting for 84.18, 6.75, 1.93 , and $7.18 \mathrm{wt} \%$, respectively.

Box-Behnken experimental design-based predictions of the DS of CMC with different combinations of the three independent variables are summarized in Table 1. According to multiple regression analysis, second order polynomial equation was obtained as shown in Eq. 4,

$$
\begin{aligned}
Y= & 1.38+\left(1.58 \times 10^{-2}\right) X_{1}+\left(4.89 \times 10^{-2}\right) X_{2}+\left(2.89 \times 10^{-2}\right) X_{3}-\left(1.28 \times 10^{-3}\right) X_{2} X_{3} \\
& -\left(8.20 \times 10^{-5}\right) X_{1}^{2}-\left(5.28 \times 10^{-3}\right) X_{2}^{2}-\left(5.91 \times 10^{-3}\right) X_{3}^{2}
\end{aligned}
$$

where $Y, X_{1}, X_{2}$, and $X_{3}$ denote the DS, NaOH concentration $(\mathrm{g} / 100 \mathrm{~mL}), \mathrm{MCA}$ dose $(\mathrm{g} / \mathrm{g}$ cellulose) and etherification time (min), respectively.

The results revealed the significance of the regression model; $p$-values lower than 0.05 implied that the $X_{1}, X_{2}, X_{3}, X_{2} X_{3}, X_{1}{ }^{2}, X_{2}{ }^{2}$ and $X_{3}{ }^{2}$ terms of the model were significant independent variables of the DS with $\mathrm{R}^{2}=0.993$. The results also indicated that the model was significant at $95 \%$ confidence level. This quadratic regression model predicted the maximum DS as 0.80. Such a DS value was obtained when the etherification reaction was carried out using $50 \mathrm{~g} / 100 \mathrm{~mL}$ of $\mathrm{NaOH}, 8 \mathrm{~g}$ of MCA/g cellulose, and etherification time of $16 \mathrm{~min}$ at input microwave power of $320 \mathrm{~W}$. To verify the predicted result, five duplicated experiments were conducted at the optimal synthesis condition; the average DS was noted to be 0.78 .

Results on the comparison of the yield of $\alpha$-cellulose, purity of CMC as well as DS of the as-synthesized CMC with those of CMC synthesized by various other raw materials and methods are given in Table 2. The as-synthesized CMC possessed similar levels of $\alpha$ cellulose yield as well as purity of CMC and DS when compared with CMC prepared from selected other lignocellulosic wastes. Purity of the as-synthesized CMC was $93.32 \%$; such a value meets the requirement of the GB/T1904-2005 standard (Zhang et al. 2011). 
Table 1. Variance Analysis of Regression Equation

\begin{tabular}{|c|c|c|c|c|c|}
\hline Source & Sum of Square & $\mathrm{Df}^{*}$ & Mean Square & $F$-value & $p$-value \\
\hline Model & 0.5773 & 9 & 0.0641 & 87.47 & $<0.0001$ \\
\hline $\mathrm{X}_{1}$ & 0.4540 & 1 & 0.4540 & 618.97 & $<0.0001$ \\
\hline $\mathrm{X}_{2}$ & 0.0057 & 1 & 0.0057 & 7.79 & 0.0269 \\
\hline $\mathrm{X}_{3}$ & 0.0133 & 1 & 0.0133 & 18.18 & 0.0037 \\
\hline $\mathrm{X}_{1} \mathrm{X}_{2}$ & 0.0029 & 1 & 0.0029 & 3.89 & 0.0892 \\
\hline $\mathrm{X}_{1} \mathrm{X}_{3}$ & 0.0006 & 1 & 0.0006 & 0.8010 & 0.4005 \\
\hline $\mathrm{X}_{2} \mathrm{X}_{3}$ & 0.0156 & 1 & 0.0156 & 21.30 & 0.0024 \\
\hline $\mathrm{X}_{1}{ }^{2}$ & 0.0045 & 1 & 0.0045 & 6.12 & 0.0426 \\
\hline $\mathrm{X}_{2}{ }^{2}$ & 0.0176 & 1 & 0.0176 & 24.02 & 0.0018 \\
\hline $\mathrm{X}_{3}{ }^{2}$ & 0.0564 & 1 & 0.0564 & 76.91 & $<0.0001$ \\
\hline
\end{tabular}

Table 2. Comparison of CMC Derived from Various Raw Materials and Methods

\begin{tabular}{|l|l|c|c|c|l|}
\hline Raw material & \multicolumn{1}{|c|}{ Method } & $\begin{array}{c}\text { Yield of } \\
\alpha \text {-cellulose } \\
(\%)\end{array}$ & $\begin{array}{c}\text { Purity } \\
\text { of } \\
\text { CMC }\end{array}$ & DS & \multicolumn{1}{|c|}{ Reference } \\
\hline Pineapple leaves & $\begin{array}{l}\text { Microwave } \\
\text { heating }\end{array}$ & 86.18 & 93.32 & 0.78 & This work \\
\hline $\begin{array}{l}\text { Banana pseudo } \\
\text { stem }\end{array}$ & $\begin{array}{l}\text { Conventional } \\
\text { heating }\end{array}$ & $\mathrm{n} / \mathrm{a}$ & 98.63 & 0.75 & $\begin{array}{l}\text { Adinugraha et al. } \\
2005\end{array}$ \\
\hline Cotton stalk & $\begin{array}{l}\text { Microwave } \\
\text { heating }\end{array}$ & 87.52 & 92.00 & 0.77 & Zhang et al. 2011 \\
\hline Cotton linter waste & $\begin{array}{l}\text { Ultrasound/ } \\
\text { microwave } \\
\text { synthesis }\end{array}$ & 98.11 & 98.33 & 0.74 & $\begin{array}{l}\text { Hivechi et al. } \\
2015\end{array}$ \\
\hline $\begin{array}{l}\text { Rice stubble } \\
\text { waste }\end{array}$ & $\begin{array}{l}\text { Conventional } \\
\text { heating }\end{array}$ & 90.05 & 90.18 & 0.64 & $\begin{array}{l}\text { Rodsamran and } \\
\text { Sothornvit 2020 }\end{array}$ \\
\hline
\end{tabular}

The influence of each independent variable on the DS of the as-synthesized CMC is described using response surface plots shown in Fig. 1(a-c). DS is a major factor indicating water solubility and viscoelastic properties of CMC (Panchan and Niamnuy 2015). Therefore, it was chosen as the dependent variable to denote the CMC quality in this work. Since $\mathrm{NaOH}$ concentration plays an important role in the swelling of the cellulose structure and affects the reactivity of the hydroxyl group on the cellulose chain (Zhang et al. 2011), the isolated cellulose was treated, in the first step, with $\mathrm{NaOH}$ at concentrations ranging from 10 to $50 \mathrm{~g} / 100 \mathrm{~mL}$; alkalization reaction was therefore performed. The product of this reaction is typically called alkali-cellulose (Na-cellulose), which is highly reactive towards MCA added in the following step (Ambjörnsson et al. 2013). Note that MCA is an etherifying agent that substitutes the hydroxyl group of cellulose with its carboxyl group (Tasaso 2015). $\mathrm{NaOH}$ reacts with $\mathrm{MCA}$ to form substantial amount of sodium glycolate and sodium chloride by-product. Therefore, when the $\mathrm{NaOH}$ concentration and MCA dose increased, DS also increased (see Eq. 4). Excess amount of MCA would nevertheless lead to the formation of sodium glycolate by-product from the side reaction and hence the decreased formation of CMC with lower DS value (Jia et al. 2016). Extended etherification time, on the other hand, enhances the diffusion of MCA to the cellulose structure. Contact time between MCA and the activated hydroxyl group of the cellulose would also increase, leading to an increase in the DS value. However, when the etherification time was longer than 16 min under the microwave heating at 320 W, DS was noted to decrease (Figs. $1 \mathrm{~b}$ and 1c). This is probably due to the fact that the 
structure of cellulose or the completely formed CMC were destroyed when the reaction was conducted under extended microwave heating (Zhang et al. 2011; Panchan et al. 2018).
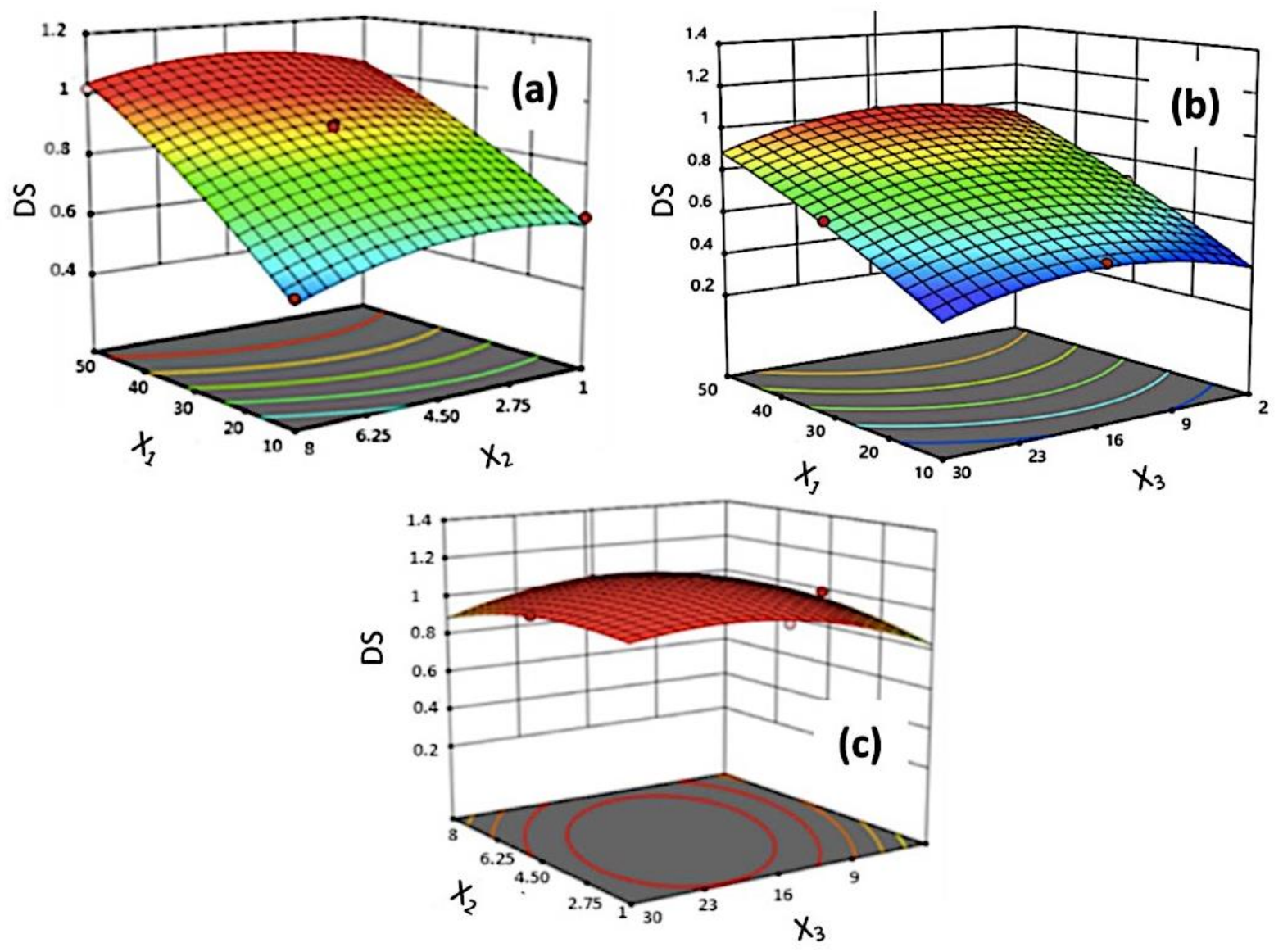

Fig. 1. 3-dimensional response surface plots for analysis of combined effect of independent variables on DS. (a) $\mathrm{NaOH}$ concentration $\left(X_{1}\right)$ and MCA dose $\left(X_{2}\right)$, (b) $\mathrm{NaOH}$ concentration $\left(X_{1}\right)$ and time $\left(X_{3}\right)$ and $(c)$ MCA dose $\left(X_{2}\right)$ and time $\left(X_{3}\right)$

\section{Characterization of As-Synthesized CMC}

$\mathrm{XRD}$ patterns of isolated cellulose, alkali-cellulose, and as-synthesized CMC from pineapple leaves shown in Fig. 2 signify the differences in microstructures of these samples. Diffractogram of the isolated cellulose displayed main peaks at $2 \theta=14.8^{\circ}, 16.4^{\circ}$, $22.5^{\circ}$, and $34.7^{\circ}$, which are, respectively, the positions of (101), (101), (200), and (040) crystallographic planes typically assigned to cellulose I (Santos et al. 2015; Carrillo-Varela et al. 2018). After alkalization, the diffractogram peaks shifted to $2 \theta=12.1^{\circ}, 20.2^{\circ}, 22.0^{\circ}$ and $37.1^{\circ}$, which correspond to the positions of (101), (101), (200), and (040) crystallographic planes, which are typical of the cellulose II polymorph (Mansikkamäki et al. 2005; Oudiani et al. 2011). Such shifts indicated that the crystalline form of cellulose changed during the alkalization reaction (Su et al. 2019). When focusing on the assynthesized CMC, it is clear that the characteristic peaks of cellulose had almost disappeared. This indicated the transformation into an amorphous phase due to the cleavage of hydrogen bonds upon being treated with $\mathrm{NaOH}$ (Panchan and Niamnuy 2015). 
Crystallinity index (CrI) values of isolated cellulose, alkali-cellulose, and assynthesized CMC were noted to be $93.98 \%$, 69.16\%, and 49.85\%. Crystallinity of the samples decreased after alkalization and etherification due to the transformation and destruction of the crystalline cellulose (Wei et al. 2019). XRD patterns of the assynthesized CMC and commercial CMC were noted to be almost similar. Crystallinity indices of the as-synthesized CMC and commercial CMC were $49.85 \%$ and $52.03 \%$, respectively. $\mathrm{CrI}$ of the as-synthesized CMC was different from those of CMC prepared from other raw materials, namely, banana pseudo stem and cotton linter waste, which had the crystallinity indices of 7.37 and 38, respectively (Adinugraha et al. 2005; Hivechi et al. 2015). Such observations are due to the fact that CrI does not depend only on DS, but also on the distribution of substituents within the anhydroglucose unit (AGU), molecular weight and polysaccharide chain structure, among other factors. These parameters are related to the type of raw materials, ratio of reactants and synthesis method (Mondal et al. 2015; Cai et al. 2018; Rahman et al. 2021).

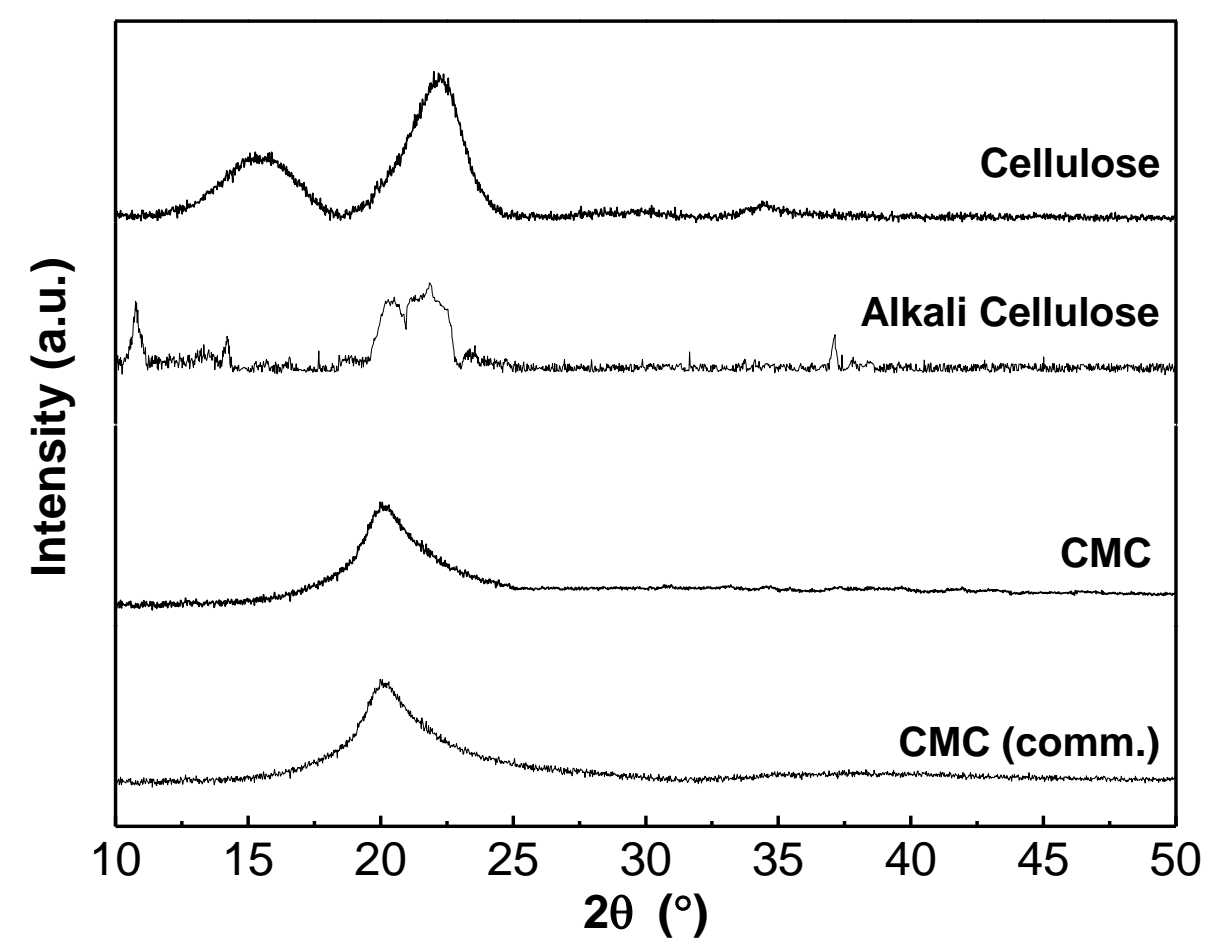

Fig. 2. XRD patterns of cellulose, alkali-cellulose, as-synthesized CMC and commercial CMC

FTIR spectra of cellulose, alkali-cellulose, and as-synthesized CMC are shown in Fig. 3. The peak appearing between 3700 to $3000 \mathrm{~cm}^{-1}$ is correlated with the hydroxyl group presented in cellulose, alkali-cellulose and CMC. The peaks appearing at 1060, 1112 and $1162 \mathrm{~cm}^{-1}$ correspond to the $-\mathrm{O}$ - stretching vibrations of the hydroxyl group of cellulose, stretching vibrations of ether bonds in the cellulose molecule, and stretching vibration of the ether bond (C-O-C) on the cellulose skeleton, respectively. The stronger peaks at 1430 and $1600 \mathrm{~cm}^{-1}$ are related to the asymmetric and symmetric vibrations of $\mathrm{COO}^{-}$(carboxylate group), indicating the presence of the carboxymethylated anion in the cellulose structure. The peak at $1340 \mathrm{~cm}^{-1}$ represents the $\mathrm{C}-\mathrm{H}$ bending, which could help confirm the formation of Na-cellulose and Na-CMC during the alkalization and etherification steps (Santos et al. 2015; Wei et al. 2019; Chagas et al. 2020). The intensity 
of the peak at $900 \mathrm{~cm}^{-1}$ increased after the alkalization step. This result indicated the transformation of the crystalline structure of cellulose-I to II.

Similar spectra belonging to the as-synthesized CMC and commercial CMC could be observed. The as-synthesized cellulose also exhibited similar spectra to CMC prepared from other lignocellulosic biomasses (Adinugraha et al. 2005; Zhang et al. 2011; Hivechi et al. 2015; Rodsamran and Sothornvit 2020).

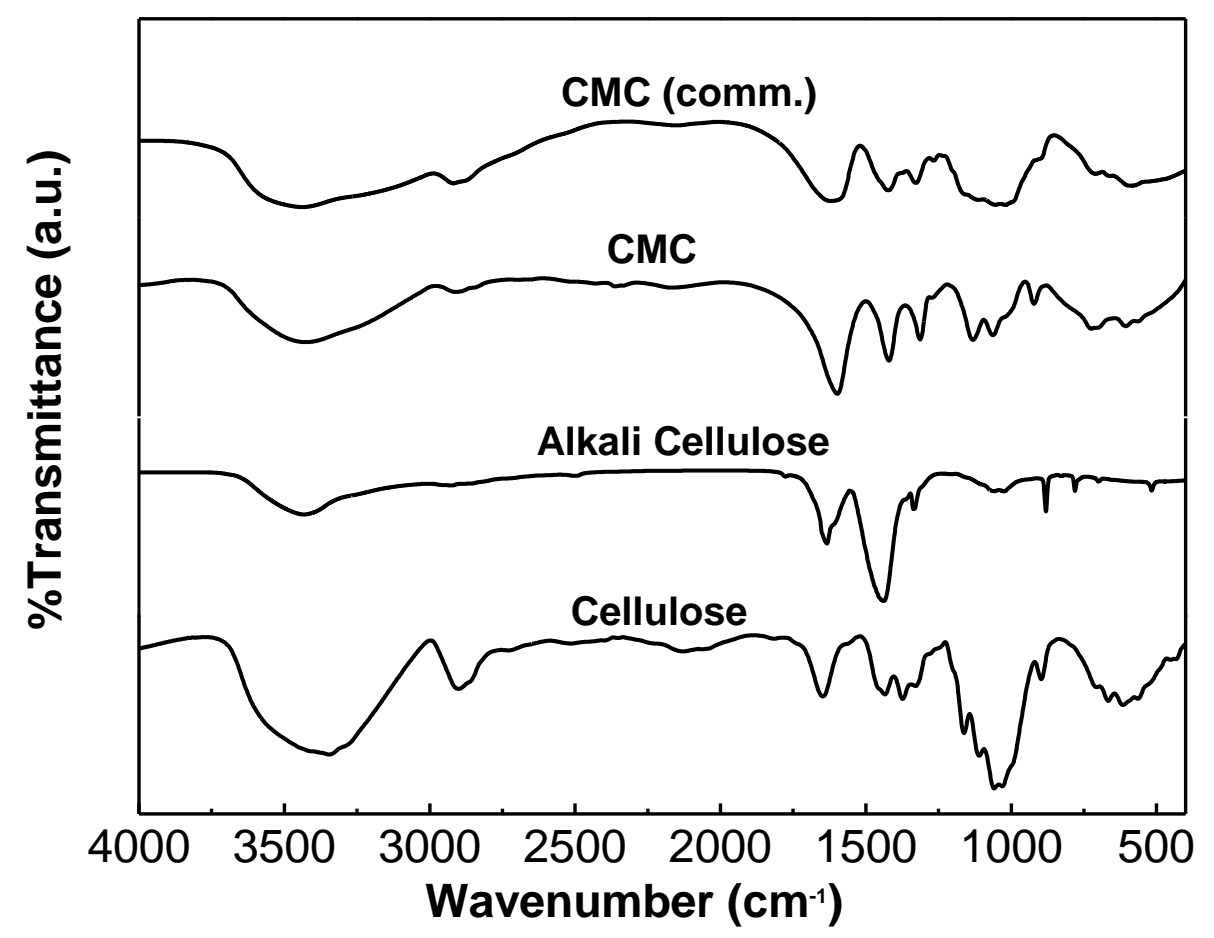

Fig. 3. FTIR spectra of cellulose, alkali-cellulose, as-synthesized CMC and commercial CMC

Morphological changes of the pineapple leaf fibers during different treatment stages were observed via scanning electron microscopy (Fig. 4). Untreated pineapple leaves exhibited rigid and highly ordered fibers, with diameters of around $35 \mu \mathrm{m}$. On the other hand, treated fibers possessed cellulose fiber bundles, with individual fibers having average diameters of around $6 \mu \mathrm{m}$ (Fig. 4b); these changes are due to progressive removal of non-cellulosic layers. Figure 4(c) illustrates the regular and relatively smooth surface of the as-synthesized CMC, with approximate diameters of $29 \mu \mathrm{m}$. Such morphological characteristics are attributed to the bulky carboxymethyl group introduced into the surface of the cellulose fiber during the carboxymethylation reaction step (Santos et al. 2015).

Solubility and viscosity of the as-synthesized CMC were determined using water at $30{ }^{\circ} \mathrm{C}$. The results are summarized in Table 3 . The solubility decreased and viscosity increased when the CMC concentration increased. 

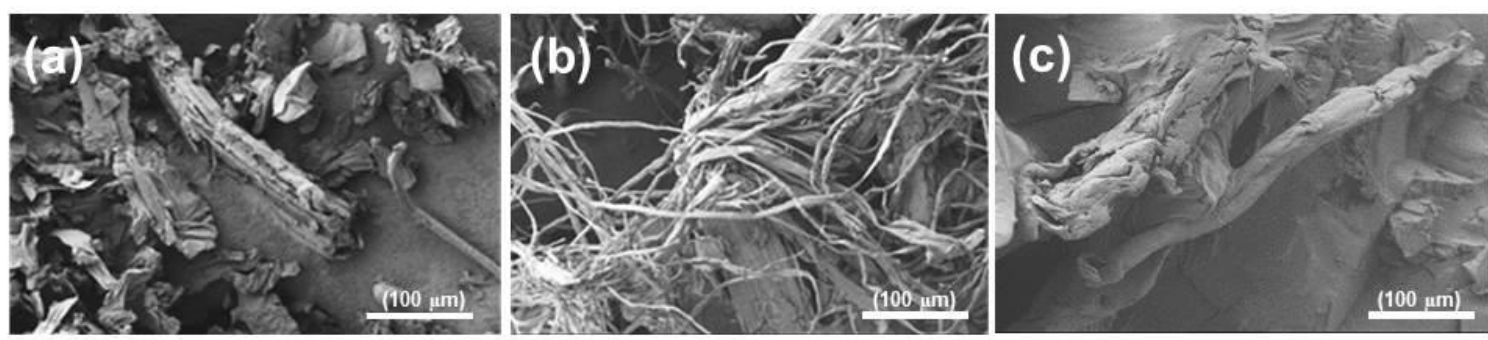

Fig. 4. Scanning electron microscopic images of (a) untreated dried pineapple leaf powder, (b) cellulose and (c) as-synthesized CMC.

Table 3. Solubility and Viscosity of as-synthesized CMC in Water at $30^{\circ} \mathrm{C}$

\begin{tabular}{|c|c|c|}
\hline Concentration of CMC (\%) & Solubility $(\mathrm{g} / 100 \mathrm{~mL})$ & Viscosity $(\mathrm{cP})$ \\
\hline 0 & $\mathrm{n} / \mathrm{a}$ & 0.89 \\
\hline 0.3 & 92.67 & 18.33 \\
\hline 1 & 90.80 & 66.80 \\
\hline 2 & 89.00 & 111.00 \\
\hline
\end{tabular}

\section{Flow Behavior of As-Synthesized CMC}

Commercial food thickener (Resource, Nestle, Linda-a-Velha, Portugal) consisting of maltodextrin and xanthan gum was used as the reference thickener. Apparent viscosities of the as-synthesized CMC and commercial thickener solutions at $2 \mathrm{wt} \%$ concentration are shown in Fig. 5. The apparent viscosities of the as-synthesized CMC were very close to those of the commercial thickener. The two samples also exhibited similar behaviors, in that the viscosity decreased with the increased shear rate, indicating that both samples exhibited the shear-thinning behavior. These observations agree with those of Yang and Zhu (2007) and Arancibia et al. (2013). The observed changes can be interpreted as the result of the disruption of molecular entanglements of polymer coils upon increasing the shear rate (Chang et al. 2017).

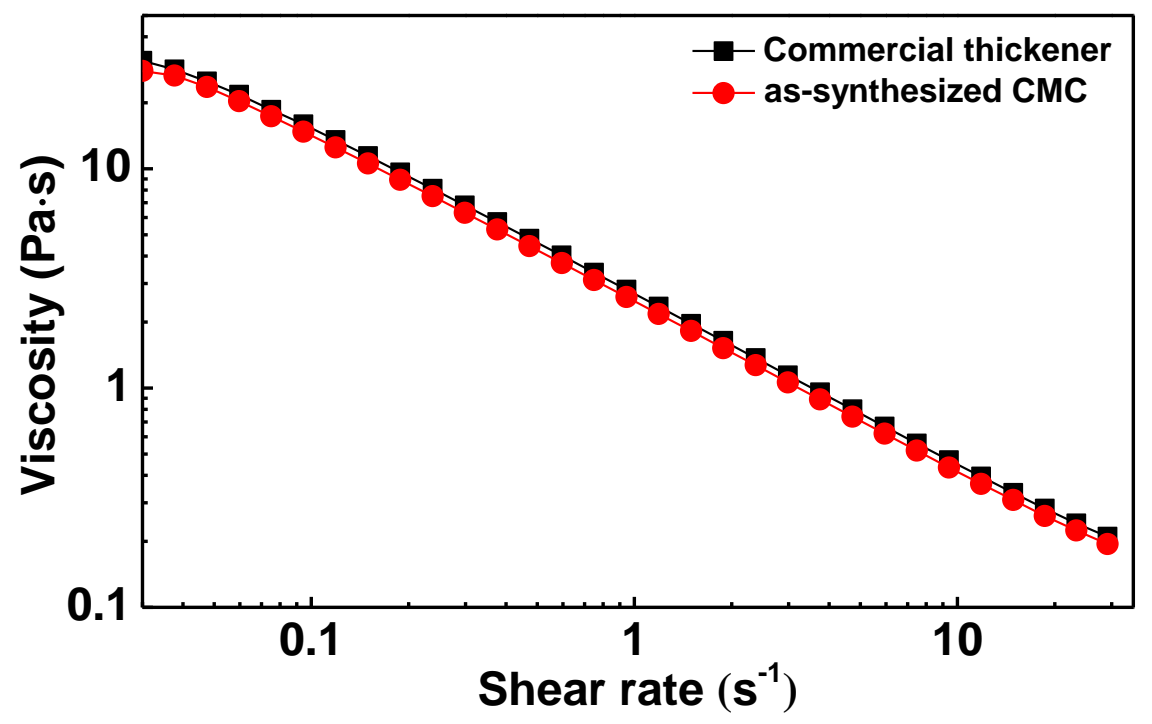

Fig. 5. Apparent viscosity changes of as-synthesized $\mathrm{CMC}$ and commercial thickener at $25^{\circ} \mathrm{C}$ and shear rates of 0.03 to $30 \mathrm{~s}^{-1}$ 
Figure 6 shows the plots between the shear stress $(\sigma)$ and shear rate $(j)$ of both the as-synthesized CMC and commercial thickener. The experimental data were well fitted to the Power-law model $\left(\mathrm{R}^{2}=0.9914-0.9924\right)$; the rheological constants are listed in Table 4. The values of the flow behavior index $(n)$ of both the as-synthesized CMC and commercial thickener samples were less than 1, indicating the shear-thinning behavior of both samples. Such a behavior is also typical of a food thickener (Seo and Yoo 2013; Yoon and Yoo 2017). The consistency index $(K)$ reflects the viscosity of CMC solution; $K$ value of the assynthesized CMC was smaller than that of the commercial CMC. This implied that the commercial thickener would lead to a slower movement of thickened water through oropharynx during swallowing when compared with the as-synthesized CMC (Pedersen $e t$ al. 2016, Jeong et al. 2019).

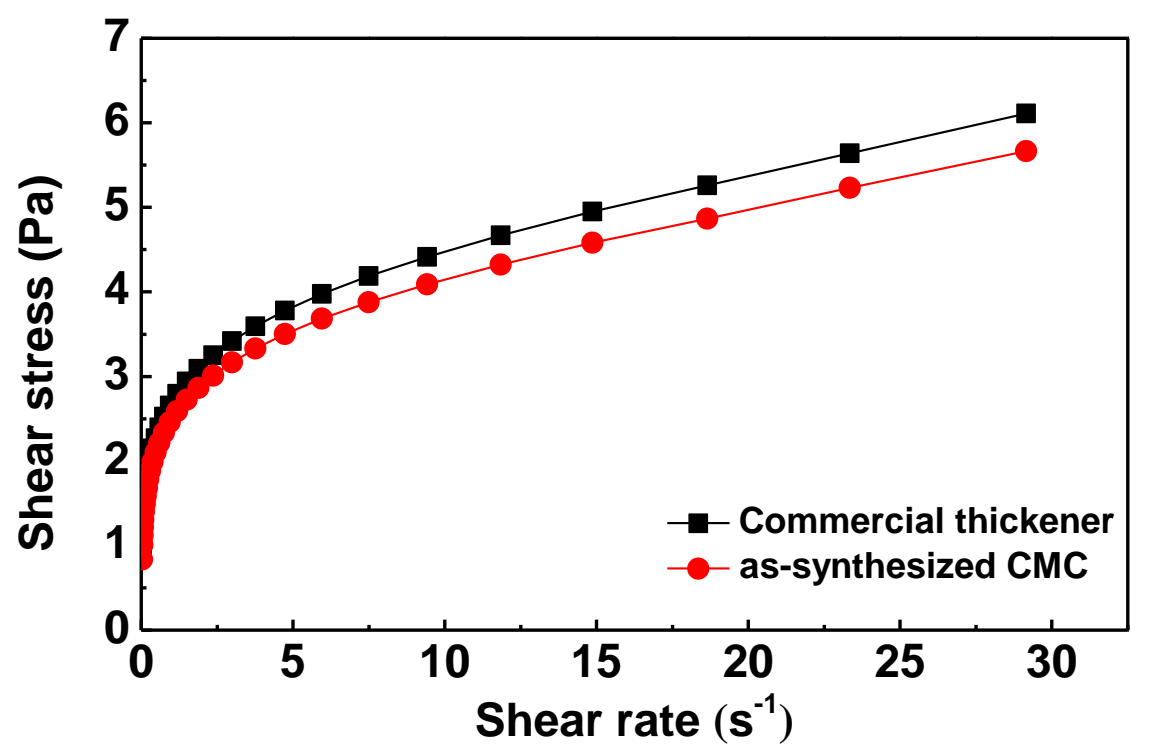

Fig. 6. Flow behaviors of as-synthesized $\mathrm{CMC}$ and commercial thickener at $25^{\circ} \mathrm{C}$ and shear rates of 0.03 to $30 \mathrm{~s}^{-1}$

Table 4. Power-law Model Constants of As-synthesized CMC and Commercial Thickener

\begin{tabular}{|l|c|c|c|}
\hline \multirow{2}{*}{ Sample } & \multicolumn{3}{|c|}{ Power-law model constant } \\
\cline { 2 - 4 } & $K\left(\mathrm{~Pa} \mathrm{~s}^{\mathrm{n}}\right)$ & $n$ & $\mathrm{R}^{2}$ \\
\hline CMC & 2.4265 & 0.2469 & 0.9914 \\
\hline Commercial thickener & 2.6190 & 0.2470 & 0.9924 \\
\hline
\end{tabular}

\section{Viscoelastic Properties of As-Synthesized CMC}

$G^{\prime}$ reflects the elastic property, while $G^{\prime \prime}$ represents the viscous behavior of a material (Inglett et al. 2013). $G^{\prime}$ is of particular important as it is a parameter that reflects bolus formation for safe and easy swallowing (Jo et al. 2018). Figure 7 shows the viscoelastic behavior of water thickened by the as-synthesized CMC; the behavior of the water thickened by the commercial thickener is also illustrated. The dynamic profiles revealed the elastic over the viscous behavior. An increase in the angular frequency led to an increase in both the $G^{\prime}$ and $G^{\prime \prime}$ values; similar trends were reported by Kim et al. (2014). $G^{\prime}$ was higher than $G^{\prime \prime}$ over the entire frequency range for both thickeners, indicating their gel-like behavior (Barba et al. 2002; Moret-Tatay et al. 2015). Such a behavior has been interpreted as an entangled network among macromolecules (Lee and Yoo 2019). 
Nevertheless, the as-synthesized CMC exhibited a larger slope of the $G^{\prime}$ curve than the commercial thickener, indicating the weaker structured system of the former (Sharma et al. 2017).
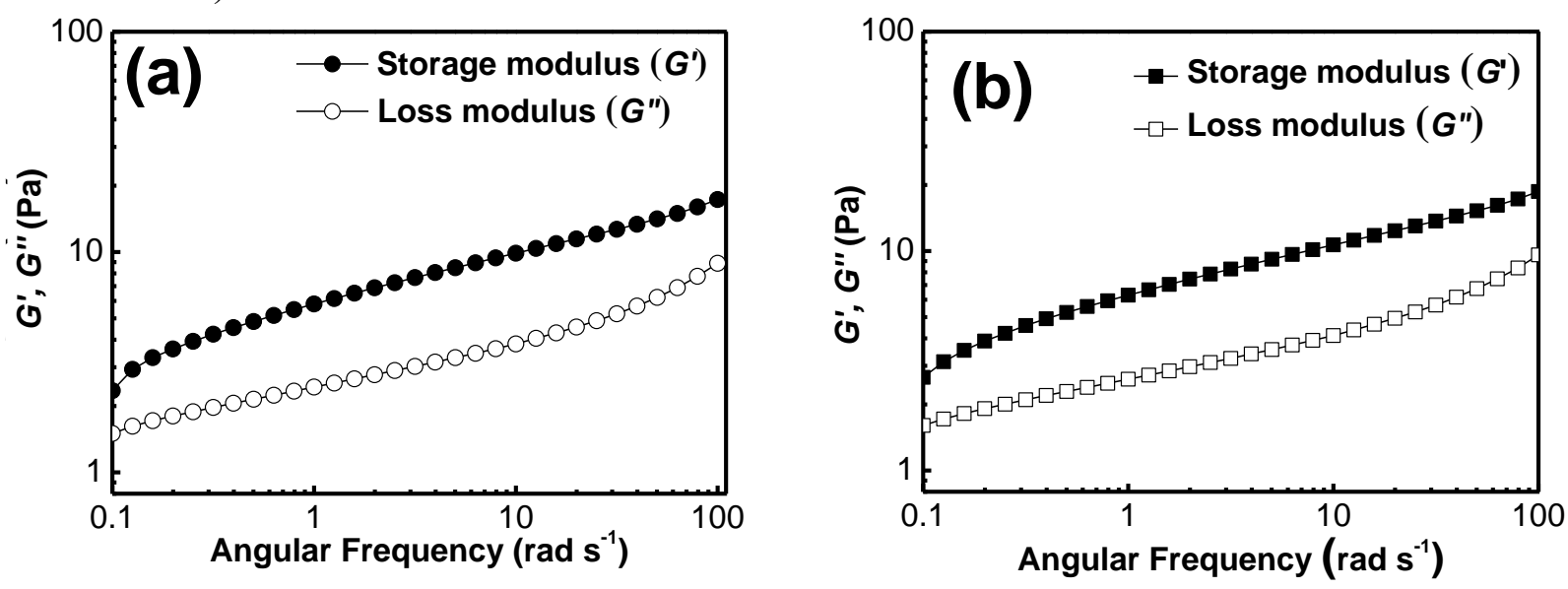

Fig. 7. Plots of storage modulus (filled symbols) and loss modulus (open symbols) versus angular frequency of (a) as-synthesized CMC from pineapple leaves and (b) commercial thickener

Experiments were conducted to evaluate the use of the as-synthesized CMC as a thickener for the selected liquid foods. The results (Table 5) illustrated that the viscosity increased by about 125, 76, and 70 folds when water, milk, and orange juice were thickened by the as-synthesized CMC. The commercial thickener increased the viscosities of the food samples by 2.15-, 2.45-, and 2.06-fold higher than the as-synthesized CMC. Such results are due to the fact that the commercial thickener contains xanthan gum, which is known for its ability to increase the viscosity of a solution even when used at a lower concentration (Desplanques et al. 2012). The above changes in the viscosity indicated that the behaviors of these foods had changed from thin liquids into nectar-thick consistency. In the case of mushroom cream soup, the viscosity increased only by about 1.6 folds; its behavior remained unchanged.

Based on the above-mentioned results, the as-synthesized CMC can be regarded as a potential thickener for water, milk, and orange juice because it could change the behaviors of these liquid foods into the desirable nectar-like consistency when being used at the same concentration as the commercial thickener. It is important to note that although the commercial thickener could more favorably increase the viscosity of the food samples than the as-synthesized CMC, xanthan gum in the commercial thickener can result in lower postprandial blood glucose when consumed at a larger dose (Fabek et al. 2014). This issue deserves careful consideration, especially in the case of elderly consumers or patients who possess swallowing and/or malnutrition issues. 
Table 5. Viscosities and Behaviors of Liquid Foods Thickened by As-synthesized $\mathrm{CMC}$ and Commercial thickener

\begin{tabular}{|l|l|c|c|c|c|c|}
\hline \multirow{1}{*}{ Sample } & \multicolumn{3}{|c|}{ Viscosity (cP) } & \multicolumn{3}{c|}{ Behavior } \\
\cline { 2 - 7 } & $\begin{array}{c}\text { Unthickened } \\
\text { sample }\end{array}$ & $\begin{array}{c}\text { Sample } \\
\text { thickened with } \\
2 \%(\mathrm{w} / \mathrm{v}) \\
\text { as-synthesized } \\
\text { CMC }\end{array}$ & $\begin{array}{c}\text { Sample } \\
\text { thickened with } \\
2 \%(\mathrm{w} / \mathrm{v}) \\
\text { commercial } \\
\text { Thickener }\end{array}$ & $\begin{array}{c}\text { Sample } \\
\text { Unthickened } \\
\text { sample } \\
\text { thickened with } \\
2 \%(\mathrm{w} / \mathrm{v}) \\
\text { as-synthesized } \\
\text { CMC }\end{array}$ & $\begin{array}{c}\text { Sample } \\
\text { thickened with } \\
2 \%(\mathrm{w} / \mathrm{v}) \\
\text { commercial } \\
\text { Thickener }\end{array}$ \\
\hline Water & $0.89 \pm 0.01^{\mathrm{c}}$ & $111.33 \pm 6.03^{\mathrm{b}}$ & $239.67 \pm 17.02^{\mathrm{a}}$ & Thin liquid & Nectar & Nectar \\
\hline $\begin{array}{l}\text { Orange } \\
\text { juice }\end{array}$ & $2.73 \pm 0.02^{\mathrm{c}}$ & $207.00 \pm 6.00^{\mathrm{b}}$ & $465.67 \pm 23.94^{\mathrm{a}}$ & Thin liquid & Nectar & Honey \\
\hline $\begin{array}{l}\text { Mushroom } \\
\text { cream } \\
\text { soup }\end{array}$ & $559.67 \pm 6.02^{\mathrm{c}}$ & $253.67 \pm 8.33^{\mathrm{b}}$ & $521.67 \pm 18.99^{\mathrm{a}}$ & Thin liquid & Nectar & Honey \\
\hline
\end{tabular}

Values with different superscript letters in the same row are significantly different $(p<0.05)$.

\section{CONCLUSIONS}

1. Carboxymethyl cellulose from pineapple leaf waste was successfully synthesized by using the optimal condition of $50 \mathrm{~g} / 100 \mathrm{~mL} \mathrm{NaOH}, 8.0 \mathrm{~g} \mathrm{MCA} / \mathrm{g}$ cellulose, and an etherification time of $16 \mathrm{~min}$ under microwave heating at $320 \mathrm{~W}$. At such a condition, the maximum degree of substitution of 0.78 was achieved.

2. As-synthesized CMC and commercial thickener exhibited similar shear-thinning behavior that is well described by the Power-law model. Such a behavior indicates its suitability as a food thickener.

3. As-synthesized CMC from pineapple leaves was characterized for its solubility and viscoelastic properties. $2 \%(\mathrm{w} / \mathrm{v})$ CMC solution was noted as a non-Newtonian fluid exhibiting gel-like behavior in much the same way as the commercial thickener at the same suitable concentration. These results also reflect the suitable viscoelastic properties of the as-synthesized CMC as a food thickener.

4. As-synthesized CMC could adequately increase the viscosity of the test liquid foods, leading to the change of their behaviors from thin-liquid into nectar-like consistency. Therefore, it can be concluded that the as-synthesized CMC from pineapple leaves can serve as a potential alternative food thickener with comparable properties and behavior to the commercial food thickener.

\section{ACKNOWLEDGEMENTS}

The authors express their sincere appreciation to the Kasetsart University Research and Development Institute (KURDI), Kasetsart University. The authors also express their appreciation to the National Science and Technology Development Agency (NSTDA) for financially supporting the study through the Chair Professor Grant (Grant No. P-2052263). 


\section{REFERENCES CITED}

Abe, T. O., Lajide, L., Owolabi, B. J., Adebayo, A. O., Ogunjobi, J. K., and Oluwasina, O. O. (2018). "Synthesis and application of carboxymethyl cellulose from Gliricidia sepium and Cola gigantea," BioResources 13, 6077-6097. DOI: 10.15376/biores.13.3.6077-6097

Adinugraha, M. P., Marseno, D. W., and Haryadi (2005). "Synthesis and characterization of sodium carboxymethylcellulose from cavendish banana pseudo stem (Musa cavendishii LAMBERT)," Carbohydrate Polymers 62, 164-169. DOI: 10.1016/j.carbpol.2005.07.019

Asl, S. A., Mousavi, M., and Labbafi, M. (2017). "Synthesis and characterization of carboxymethyl cellulose from sugarcane bagasse," Journal of Food Processing and Technology 8, 687-693. DOI:10.4172/2157-7110.1000687

Ambjörnsson, H. A., Schenzel, K., and Germgård, U. (2013). "Carboxymethyl cellulose produced at different mercerization conditions and characterized by NIR FT Raman spectroscopy in combination with multivariate analytical method," BioResources 8, 1918-1932. DOI: 10.15376/biores.8.2.1918-1932

Arancibia, C., Bayarri, S., and Costell, E. (2013). "Comparing carboxymethyl cellulose and starch as thickeners in oil/water emulsions. Implications on rheological and structural properties," Food Biophysics 8, 122-136. DOI: 10.1007/s11483-013-9287-2

Arancibia, C., Navarro-Lisboa, R., Zúñiga, R. N., and Matiacevich, S. (2016). "Application of CMC as thickener on nanoemulsions based on olive oil: Physical properties and stability," International Journal of Polymer Science 6280581. DOI: $10.1155 / 2016 / 6280581$

ASTM (1994). Standard test methods for sodium carboxymethylcellulose. Philadelphia: ASTM Committee on Standards, 291-298. (ASTM: D1439-94).

Balakrishnan, P., Gopi, S., Geethamma, V. G., Kalarikkal, N., and Thomas, S. (2018). "Cellulose nanofiber vs nanocrystals from pineapple leaf fiber: A comparative studies on reinforcing efficiency on starch nanocomposites," Macromolecular Symposia 280, 1800102-1800108. DOI: 10.1002/masy.201800102

Barba, C., Montané, D., Farriol, X., Desbriéres, J., and Rinaudo, M. (2002). "Synthesis and characterization of carboxymethylcellulose from non-wood pulps II. Rheological behaviour of CMC in aqueous solution," Cellulose 9, 327-335. DOI: 10.1023/A:1021136626028

Bayarri, S., González-Tomás, L., and Costell, E. (2009). "Viscoelastic properties of aqueous and milk systems with carboxymethyl cellulose," Food Hydrocolloids 23, 441-450. DOI: 10.1016/j.foodhyd.2008.02.002

Cai, Z., Wu, J., Du, B., and Zhang, H. (2018). "Impact of distribution of carboxymethyl substituents in the stabilizer of carboxymethyl cellulose on the stability of acidified milk drinks," Food Hydrocolloids 76, 150-157. DOI: 10.1016/j.carbpol.2005.07.019

Carrillo-Varela, I., Pereira, M., and Mendonça, R. T. (2018). "Determination of polymorphic changes in cellulose from Eucalyptus spp. fibres after alkalization," Cellulose 25, 6831-6845. DOI: 10.1007/s10570-018-2060-4

Chagas, R., Gericke, M., Ferreira, R. B., Heinze, T., and Ferreiea, L. M. (2020). "Synthesis and characterization of dicarboxymethyl cellulose," Cellulose 27, 19651974. DOI: 10.1007/s10570-019-02952-6

Chang, Y., Li Y., Miao, Q., Jiang, H., and Gao, X. (2017). "Rheological properties of six 
plant-based seed gums," American Journal of Analytical Chemistry 8, 690-707. DOI: 10.4236/ajac.2017.877051

Cherian, B. M., Leao, A. L. de Souza, S. F., Thomas, S., Pothan, L. A., and Kottaisamy, M. (2010). "Isolation of nanocellulose from pineapple fibers by steam explosion," Carbohydrate Polymers 81, 720-725. DOI: 10.1016/j.carbpol.2010.03.046

Chollakup, R., Tantatherdtam, R., Ujjin, S., and Sriroth, K. (2011). "Pineapple leaf fiber reinforced thermoplastic composites: Effects of fiber length and fiber content on their characteristics," Journal of Applied Polymer Science 119, 1952-1960. DOI: 10.1002/app. 32910

Chouhan, N., Vig, H., and Deshmukh, R. (2019). Carboxymethyl Cellulose Market by Purity Level (Highly Purified, Technical Grade, and Industrial Grade), Application (Food \& Beverages, Oil \& Refining, Pharmaceutical, Paint \& Textile, Cosmetics \& Personal Care, Paper Coating \& Household Care, and Others), and Property (Thickening Agent, Stabilizer, Binder, Anti-Repository Agent, Lubricator, Emulsifier, and Excipient): Global Opportunity Analysis and Industry Forecast, 2019-2026, Allied Market Research, (https://www.alliedmarketresearch.com/carboxymethylcellulose-market).

Desplanques, S., Renou, F., Grisel, M., and Malhiac, C. (2012). "Impact of chemical composition of xanthan gum and acacia gums on the emulsification and stability of oil-in-water emulsions," Food Hydrocolloids 27, 401-410.

DOI: 10.1016/j.foodhyd.2011.10.015

Fabek, H., Messerschmidt, S., Brulport, V., and Goff, H.D. (2014). "The effect of in vitro digestive processes on the viscosity of dietary fibres and their influence on glucose diffusion," Food Hydrocolloids 35, 718-726. DOI: 10.1016/j.foodhyd.2013.08.007

Hivechi, A., Bahrami, S. H., Arami, M., and Karimi, A. (2015). "Ultrasonic mediated production of carboxymethyl cellulose: Optimization of conditions using response surface methodology," Carbohydrate Polymers 134, 278-284. DOI: 10.1016/j.carbpol.2015.07.045

Inglett, G. E., Chen, D., Xu, J., and Lee, S. (2013). "Pasting and rheological properties of chia composites containing barley flour," International Journal of Food Science \& Technology 48, 2564-2570. DOI: 10.1111/ijfs. 12250

Jeong, G. Y., Bak, J. H., and Yoo, B. (2019). "Physical and rheological properties of xanthan gum agglomerated in fluidized bed: effect of HPMC as a binder," International Journal of Biological Macromolecules 121, 424-428. DOI: 10.1016/j.ijbiomac.2018.10.048

Jia, F., Liu, H. J., and Zhang, G. G. (2016). "Preparation of carboxymethyl cellulose from corncob," Procedia Environmental Sciences 31, 98-102. DOI: 10.1016/j.proenv.2016.02.013

Jo, W., Bak, J. H., and Yoo, B. (2018). "Rheological characterizations of concentrated binary gum mixtures with xanthan gum and galactomannans," International Journal of Biological Macromolecules 114, 263-269. DOI: 10.1016/j.ijbiomac.2018.03.105

Kappe, C. O. (2004). "Controlled microwave heating in modern organic synthesis," Angewandte Chemie 43, 6250-6284. DOI: 10.1002/anie.200400655

Kengkhetkit, N., and Amornsakchai, T. (2012). "Utilization of pineapple leaf waste for plastic reinforcement: 1. A novel extraction method for short pineapple leaf fiber," Industrial Crops and Products 40, 55-61. DOI: 10.1016/j.indcrop.2012.02.037

Kim, S. G., Yoo, W., and Yoo, B. (2014). "Effect of thickener type on the rheological 
properties of hot thickened soups suitable for elderly people with swallowing difficulty," Preventive Nutrition and Food Science 19, 358-362. DOI:

10.3746/pnf.2014.19.4.358

Klunklin, W., Jantanasakulwong, K., Phimolsiripol, Y., Leksawasdi, N., Seesuriyachan, P., Chaiyaso, T., Insomphun, C., Phongthai, S., Jantrawut, P., Sommano, S. R., Punyodom, W., Reungsang, A., Ngo, T. M. P., and Rachtanapun, P. (2021). "Synthesis, characterization, and application of carboxymethyl cellulose from asparagus stalk end," Polymers 13, 81-95. DOI: 10.3390/polym13010081

Lakshmi, D. S., Trivedi, N., and Reddy, C. R. K. (2017). "Synthesis and characterization of seaweed cellulose derived carboxymethyl cellulose," Carbohydrate Polymers 157, 1604-1610. DOI: 10.1016/j.carbpol.2016.11.042

Lee, H., and Yoo, B. (2019). "Rheological characteristics of waxy rice starch modified by carboxymethyl cellulose," Preventive Nutrition and Food Science 24, 478-484.

Mahardika, M., Abral, H., Kasim, A., Arief, S., and Asrofi, M. (2018). "Production of nanocellulose from pineapple leaf fibers via high-shear homogenization and ultrasonication," Fibers 6, 28-39. DOI: 10.3390/fib6020028

Mansikkamäki, P., Lahtinen, M., and Rissanen, K. (2005). "Structural changes of cellulose crystallites induced by mercerization in different solvent systems; determined by powder X-ray diffraction method," Cellulose 12, 233-242. DOI: 10.1007/s10570-004-3132-1

Mondal, M. I. H., Yeasmin, M. S., and Rahman, M. S. (2015). "Preparation of food grade carboxymethyl cellulose from corn husk agrowaste," International Journal of Biological Macromolecules 79, 144-150. DOI: 10.1016/j.ijbiomac.2015.04.061

Moret-Tatay, A., Rodriguez-Garcia, J., Marti-Bonmati, E., Hernando, I., and Hernandez, M. J. (2015). "Commercial thickeners used by patients with dysphagia: Rheological and structural behaviour in different food matrices," Food Hydrocolloids 51, 318326. DOI: $10.1016 /$ j.foodhyd.2015.05.019

Office of Agricultural Economics. (2020). Pineapple Factory: Cultivated area, harvest area, yield and yield per rai in 2019 by province, Office of Agricultural Economics (https://www.oae.go.th/).

Ou, S., Kwok, K., Li, Y., and Fu, L. (2001). "In vitro study of possible role of dietary fiber in lowering postprandial serum glucose," Journal of Agricultural and Food Chemistry 49, 1026-1029. DOI: 10.1021/jf000574n

Oudiani, A. E., Chaabouni, Y., Msahli, S., and Sakli, F. (2011). "Crystal transition from cellulose I to cellulose II in NaOH treated Agave americana L. fibre," Carbohydrate Polymers 86, 1221-1229. DOI: 10.1016/j.carbpol.2011.06.037

Panchan, N., and Niamnuy, C. (2015). "Preparation, optimization and characterization of carboxymethyl cellulose from rice straw using microwave heating," The $2^{\text {nd }}$ International Symposium on Agricultural Technology (ISAT2015), Chonburi, Thailand, 141-144.

Panchan, N., Niamnuy, C., Dittanet, P., and Devahastin, S. (2018). "Optimization of synthesis condition for carboxymethyl cellulose-based hydrogel from rice straw by microwave-assisted method and its application in heavy metal ions removal," Journal of Chemical Technology and Biotechnology 93, 413-425. DOI: 10.1002/jctb.5370

Pedersen, A., Wilson, J., McColl, E., Carding, P., and Patterson, J. (2016). "Swallowing outcome measures in head and neck cancer - How do they compare?," Oral Oncology 52, 104-108. DOI: 10.1016/j.oraloncology.2015.10.015 
Phan, M. T. T., Pham, L. N., Nguyen, L. H., and To, L. P. (2021). "Investigation on synthesis of hydrogel starting from Vietnamese pineapple leaf waste-derived carboxymethylcellulose," Journal of Analytical Methods in Chemistry 2021, 6639964. DOI:10.1155/2021/6639964

Pushpamalar, V., Langford, S. J., Ahmad, M., and Lim, Y. Y. (2006). "Optimization of reaction conditions for preparing carboxymethyl cellulose from sago waste," Carbohydrate Polymers 64, 312-318. DOI: 10.1016/j.carbpol.2005.12.003

Rahman, M.S., Hasan, M.S., Nitai, A.S., Nam, S., Karmakar, A.K., Ahsan, M.S., Shiddiky, M.J.A., and Ahmed, M.B. (2021). "Recent development of carboxymethyl cellulose," Polymers 13, 1345. DOI: 10.3390/polym13081345.

Rodsamran, P., and Sothornvit, R. (2020). "Carboxymethyl cellulose from rice stubble waste," Songklanakarin Journal of Science and Technology 42 (2), 454-460. DOI: 10.14456/sjst-psu.2020.59

Santos, D. M., Bukzem, A. L., Ascheri, D. P. R., Signini, R., and Aquino, G. L. B. (2015). "Microwave-assisted carboxymethylation of cellulose extracted from brewer's spent grain," Carbohydrate Polymers 131, 125-133. DOI:

10.1016/j.carbpol.2015.05.051

Santos, R. M., Neto, W. P. F., Silvério, H. A., Martin, D. F., Dantas, N. O., and Pasquini, D. (2013). "Cellulose nanocrystals from pineapple leaf, a new approach for the reuse of this agro-waste," Industrial Crops and Products 50, 707-714. DOI: 10.1016/j.indcrop.2013.08.049

Sasikala, M., and Umapathy, M. J. (2018). "Preparation and characterization of pineapple leaf cellulose nanocrystal reinforced gelatin bio-nanocomposite with antibacterial banana leaf extract for application in food packaging," New Journal of Chemistry 42, 19979-19986. DOI: 10.1039/C8NJ02973C

Seo, C.-W., and Yoo, B. (2013). "Steady and dynamic shear rheological properties of gum-based food thickeners used for diet modification of patients with dysphagia: Effect of concentration," Dysphagia 28, 205-211. DOI: 10.1007/s00455-012-9433-x

Shahbandeh, M. (2021). Leading countries in pineapple production worldwide in 2019, Statista (https://www.statista.com/statistics/298517/global-pineapple-production-byleading-countries/).

Sharma, M., Kristo, E., Corredig, M., and Duizer, L. (2017). "Effect of hydrocolloid type on texture of pureed carrot: Rheological and sensory measures," Food Hydrocolloids 63, 478-487. DOI: 10.1016/j.foodhyd.2016.09.040

Shui, T., Feng, S., Chen, G., Li, A., Yuan, Z., Shui, H., Kuboki, T., and Xu, C. (2017). "Synthesis of sodium carboxymethyl cellulose using bleached crude cellulose fractionated from cornstalk," Biomass and Bioenergy 105, 51-58. DOI: 10.1016/j.biombioe.2017.06.016

Su, L., Ou, Y., Feng, X., Lin, M., Li, J. Liu, D., and Qi, H. (2019). "Integrated production of cellulose nanofibers and sodium carboxymethylcellulose through controllable ecocarboxymethylation under mild conditions," ACS Sustainable Chemistry and Engineering 7, 3792-3800. DOI: 10.1021/acssuschemeng.8b04492

Tangtubtim, S., and Saikrasun, S. (2019). "Adsorption behaviour of polyethyleneimine carbamate linked pineapple leaf fiber for Cr(VI) removal," Applied Surface Science 467-468, 596-607. DOI: 10.1016/j.apsusc.2018.10.204

TAPPI T203om-88 (1992). “Alpha, beta, and gamma cellulose in pulp,” TAPPI Press, Atlanta, GA. 
Tasaso, P. (2015). “Optimization of reaction conditions for synthesis of carboxymethyl cellulose from oil palm fronds," International Journal of Chemical Engineering and Applications 6, 101-104. DOI: 10.7763/IJCEA.2015.V6.460

Wei, J., Zhou, Y., Lv, Y., Wang, J., Jia, C., Liu, J., Zhang, X., Sun, J., and Shao, Z. (2019). "Carboxymethyl cellulose nanofibrils with a treelike matrix: Preparation and behaviour of Pickering emulsions stabilization," ACS Sustainable Chemistry \& Engineering 7(15), 12887-12896. DOI: 10.1021/acssuschemeng.9b01822

Yang, X. H., and Zhu, W. L. (2007). "Viscosity properties of sodium carboxymethyl cellulose solutions," Cellulose 14, 409-417. DOI: 10.1007/s10570-007-9137-9

Yoon, S.-N., and Yoo, B. (2017). "Rheological behaviors of thickened infant formula prepared with xanthan gum-based food thickeners for dysphagic infants," Dysphagia 32, 454-462. DOI: 10.1007/s00455-017-9786-2

Yu, P., Hou, Y., Zhang, H., Zhang, W., Yang, S., and Ni, Y. (2019). “Characterization and solubility effects of the distribution of carboxymethyl substituents along the carboxymethyl cellulose molecular chain," BioResources 14, 8923-8934. DOI: 10.15376/biores.14.4.8923-8934

Zhang, G. L., Zhang, L., Deng, H., and Sun, P. (2011). "Preparation and characterization of sodium carboxymethyl cellulose from cotton stalk using microwave heating," Journal of Chemical Technology and Biotechnology 86, 584-589. DOI: 10.1002/jctb.2556

Article submitted: April 11, 2021; Peer review completed: July 17, 2021; Revised version received and accepted: September 21, 2021; Published: September 29, 2021.

DOI: 10.15376/biores.16.4.7684-7701 